\title{
67. Some Observations on the Microsome Fraction of Biopsied Muscle from Patients with Progressive Muscular Dystrophy*)
}

\author{
By Hideo Sugita, Kyoko Okimoto, and Setsuro Ebashi \\ Department of Neurology, Institute of Brain Research, The \\ IIIrd Department of Internal Medicine, and Department \\ of Pharmacology, Faculty of Medicine, \\ University of Tokyo
}

(Comm. by Shigeo OKINaKa, M.J.A., March 12, 1966)

Recently a keen interest has been focused on the physiology of the sarcoplasmic reticulum, which plays an important role in regulating the contraction-relaxation cycle through its unique ATP-dependent Ca-binding capacity. ${ }^{1)}$ However, no biochemical studies have so far been made on the system of muscles affected by progressive muscular dystrophy (DMP).

In the present communication we will present some preliminary observations on the ATPase activity and Ca-binding capacity of the isolated fraction of the sarcoplasmic reticulum from patients with DMP. Biopsied materials from patients with polymyositis and neurogenic amyotrophy were also examined.

Materials and Methods. About one gram of muscle was biopsied from the quadriceps muscle of the patients with DMP, polymyositis and neurogenic amyotrophy. Biopsied muscle was added to nine volumes of $0.02 \mathrm{M}$ or $0.005 \mathrm{M} \mathrm{NaHCO}_{3}$ and homogenized in a Waring Blendor of a small size. Then the homogenate was centrifuged at $4,000 \times g$ for 30 minutes and resulting supernatant was used as the preparation of the microsome fraction (the principle responsible for the $\mathrm{Mg}$-activated ATPase in the supernatant was completely sedimented at $50,000 \times g$ for 1 hour).

ATPase activity and Ca-binding capacity were determined according to the method described in the previous paper ${ }^{2)}$ and expressed on the basis of non-collagenous protein of the original muscle from which the samples were derived.

Results. In addition to the sarcoplasmic reticulum ATPase, the microsome fraction might contain two other different ATPases, i.e., mitochondrial ATPase and Na-K-dependent membrane ATPase. As is already shown, the sarcoplasmic reticulum ATPase is inhibited by $\mathrm{Ca}$ ion but not influenced by oligomycin. On the other hand, the

*) Supported by the grant from Muscular Dystrophy Associations of America, Inc. awarded to Prof. S. Okinaka. 
mitochondrial ATPase is depressed by oligomycin but not by $\mathrm{Ca}$ ion. ${ }^{3)}$

The ATPase activity of the microsome fraction was considerably decreased by Ca ion, as shown in Fig. 1., but scarcely influenced by oligomycin. The supernatant of the $0.02 \mathrm{M} \mathrm{NaHCO}_{3}$ homogenate showed higher succinic dehydrogenase activity measured by phenazine methosulfate method ${ }^{4}$ than that of $0.005 \mathrm{M} \mathrm{NaHCO}$ homogenate, whereas the former had even lower Mg-ATPase activity than the latter.

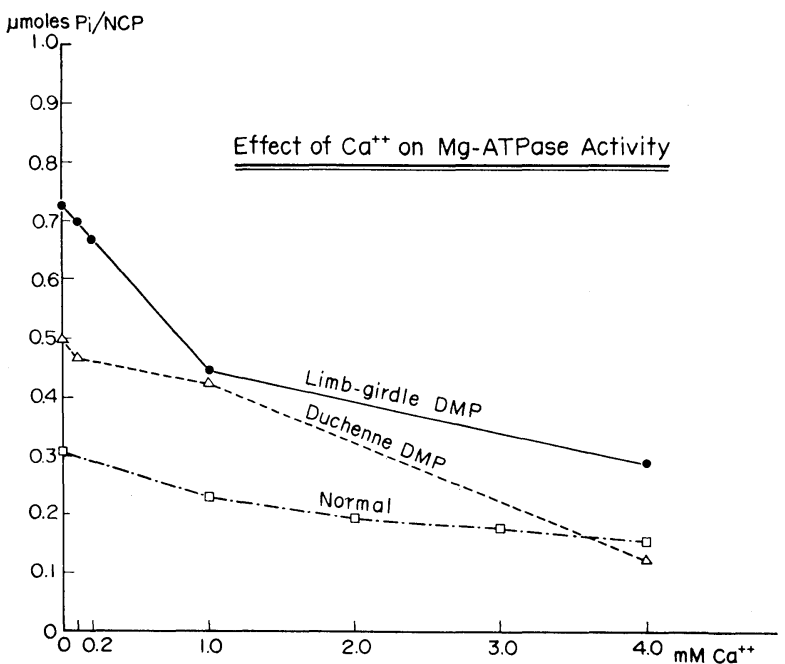

Fig. 1. Effect of $\mathrm{Ca}$ ion on Mg-ATPase activity of microsome fraction.

Each milliliter of the reaction mixture for the determination of ATPase contained: $4 \mu$ moles of $\mathrm{MgSO}_{4}, 100 \mu$ moles of $\mathrm{KCl}$, $20 \mu$ moles of Tris-maleate ( $\mathrm{pH} 6.8), 1 \mu$ mole of ATP, $0.025 \mathrm{ml}$ of microsome fraction (see the text) and specified amounts of $\mathrm{Ca}$ ion. The enzyme activity was expressed by the number of $\mu$ moles of inorganic phosphate hydrolysed at $37^{\circ} \mathrm{C}$. from ATP per hour per mg of non-collagenous protein of original muscle.

All these facts clearly indicate that the contaminated mitochondria, if it is present, plays only a minor part in the ATPase activity. Furthermore, the ATPase of this fraction was not influenced by $\mathrm{Na}$ and $\mathrm{K}$ ions. Therefore, it may be concluded that $\mathrm{Mg}$-activated ATPase of the microsome fraction consists mainly, if not all, of the sarcoplasmic reticulum ATPase.

Mg-activated ATPase activities and Ca-binding capacities of microsome fractions from the muscle of patients with DMP and polymyositis were shown in Fig. 2. Mg-activated ATPase activities of DMP and polymyositis were definitely increased $(\mathrm{P}<0.01)$. No 


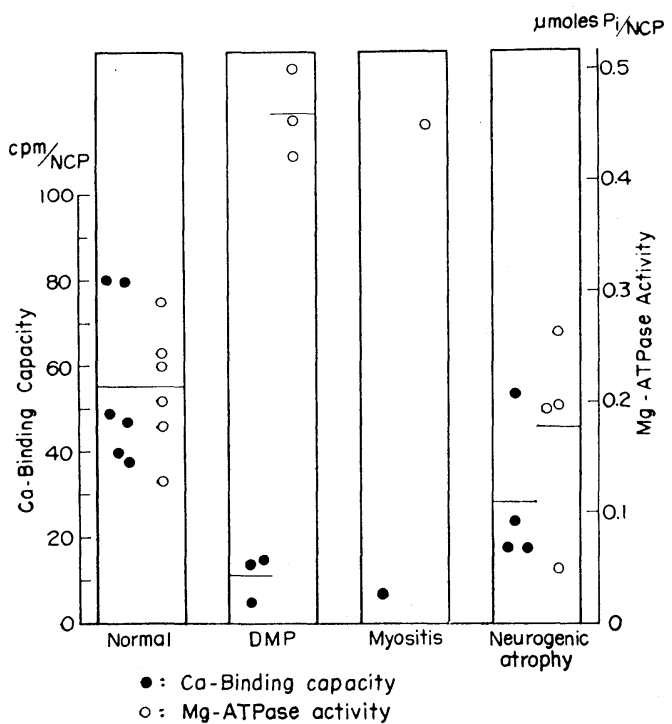

Fig. 2. Mg-ATPase and ${ }^{45} \mathrm{Ca}$-binding capacity of microsome fraction of affected muscles of DMP, polymyositis and neurogenic amyotrophy.

Each milliliter of the reaction mixture for ${ }^{45} \mathrm{Ca}$ binding capacity contained: $4 \mu$ moles of $\mathrm{MgSO}_{4}, 100 \mu$ moles of $\mathrm{KCl}, 0.01 \mu$ mole of $\mathrm{CaCl}_{2}$ (containing ${ }^{45} \mathrm{Ca}$ ), $20 \mu$ moles of Tris-maleate (pH 6.8), $1 \mu$ mole of ATP and $0.09 \mathrm{ml}$ of microsome fraction. ${ }^{45} \mathrm{Ca}$-binding capacity was expressed by the number of counts per minute of accumulated ${ }^{45} \mathrm{Ca}$ per $\mathrm{mg}$ of non-collagenous protein of original muscle.

elevation was demonstrated with the preparations from the patients with neurogenic amyotrophy.

Ca-binding capacity of the microsome fractions of affected muscles from patients with DMP and polymyositis were intensely decreased in comparison with normal subjects $(\mathrm{P}<0.01)$. In neurogenic amyotrophy, some cases also showed decreased activities. However, it must be emphasized that the depressed Ca-binding capacities were not accompanied with the elevation of ATPase activities.

Discussion and Conclusion. It has been shown that if the sarcoplasmic reticulum of rabbit muscle is denatured in vitro by a mild procedure, for instance, aging in the cold or the desoxycholate treatment of a specified concentration, its ATPase is increased with a simultaneous decrease of Ca-binding. ${ }^{2}{ }^{2}$ Therefore, the paradoxical behavior of the microsome fraction derived from patients with DMP and polymyositis, i.e., the increase of $\mathrm{Mg}$-ATPase accompanied with the decrease of Ca-binding, suggests that some degenerative process might have taken place in the sarcoplasmic reticulum. In this 
respect, it is worthy of noting that van Breemen ${ }^{5)}$ has observed the vacuolation of the sarcoplasmic reticulum as an early manifestation of the disease using electronmicroscope.

One of the most important features of DMP on the cellular level is the increased permeability of muscle cells which results in the leakage of considerable amounts of cell constituents including sarcoplasmic enzymes. The most plausible site for this leakage is, of course, the surface membrane. In view of the above results, however, the idea that the sarcoplasmic reticulum, a part of which is in contact with the external fluid, would also be liable for the anomalous leakage should not be dropped until it has been disproved conclusively.

The detail of this communication will be published elsewhere.

Acknowledgement. We would like to express our cordial thanks to Profs. S. Okinaka and K. Nakao for their warm encouragement and advice to this work.

\section{References}

1) Ebashi, S.: Progr. Theor. Physics, Suppl. 17, 35 (1961).

2) Ebashi, S., and Lipmann, F.: J. Cell Biol., 14, 398 (1962).

3) Muscatello, U., Andersson-Cedergren, E., Azzone, G. F., and Von Der Decken, A.: J. Biophysic. and Biochem. Cytol., Suppl. 10, 201 (1961).

4) Ells, H. A.: Arch. Biochem. and Biophys., 85, 561 (1959).

5) van Breemen, V. L.: Amer. J. Pathol., 37, 333 (1960). 